\title{
Co-expression of CXCR4 and CD133 in gastric neoplastic tissue and their correlation with clinicopathological factors and prognosis in gastric cancer
}

\author{
Snigdha Poddar ${ }^{1}$, Lawrence D'Cruze ${ }^{2}$, Devaraj Halagowder ${ }^{1}$ \\ ${ }^{I}$ Department of Zoology, Unit of Biochemistry, School of Life Science, University of Madras, \\ Maraimalai Campus, Guindy, Chennai, Tamil Nadu, India \\ ${ }^{2}$ Department of Pathology, Sri Ramachandra Medical College, Porur, Chennai, Tamil Nadu, India
}

Received March 17, 2015; Revised April 11, 2015; Accepted April 28, 2015; Published Online June 19, 2015

\section{Original Article}

\begin{abstract}
Purpose: Worldwide Gastric carcinoma considered as the second most common cause of cancer related death. Cancer stem cell plays significant role in prognosis and invasion of gastric cancer. CXCR4 is a chemokine receptor and plays an important role in self renewal, differentiation potential, and cell adhesion of cancer stem cell (CSC). On the other hand CD133 is a cell surface glycoprotein and could serve as a prognostic indicator for tumor re-growth, malignant progression, and patient survival. The aim of this study was to establish the expression pattern of CXCR4 and CD133 in gastric cancer tissues; and their correlation with clinicopathological factors like age and gender of patients, position, size and depth of tumor, lymphatic invasion and node metastasis. Methods: Expression of CXCR4 and CD133 proteins were assessed by immunohistochemical and immunofluorescence staining of paraffin-embedded tissues, and followed by RT-PCR in 90 tumors (observed group) and 30 normal gastric samples. The clinical pathological data was statistically analyzed by chi-square methods. Results: The positive rate of CXCR4 and CD133 expression in the observed group was 94.44 (85/90) and 95.55 (86/90), respectively. The expression of CXCR4 and CD133 were correlated with age and gender of patients, and position, size, \& depth of the tumor, lymphatic invasion and node metastasis $(p<0.05)$. While CXCR4 was positive, CD133 had a positive rate of $92.22 \%$ but the positive rate was $2.22 \%$ when CXCR4 expression was negative $\left(\chi^{2}=58.657 ; p<0.001\right)$. Conclusion: Overall this data suggests that increased expression of CXCR4 and CD133 might be attributed with disease progression and malignant transformation of gastric epithelium cells. A significant correlation was found in between CXCR4 and CD133 expression and their co-expression may play significant role in invasiveness of gastric cancer.
\end{abstract}

Keywords: Cancer Stem Cell; Gastric Cancer; CXCR4; CD133; Immunohistochemical Study; Co-immunolocalisation; RT-PCR

\section{Introduction}

Gastric cancer (GC) is one of the commonest forms of malignancies in the world. Pathogenesis of gastric cancer is associated with activation of oncogenes, inactivation of tumor suppressor genes and deregulation of cellular signal pathways. The gastric epithelial cells undergo stepwise morphologic changes before malignant transformation and multiple signaling pathways have been known to be involved in this carcinogenic process. In tumor, a small subpopulation of transformed stem cell termed as cancer stem cell plays significant role in maintenance of stemness as well as survival of the tumor cells.

CXCR4 is a chemokine receptor and was first identified as a regulator of the homing of lymphocytes in inflammatory tissues. ${ }^{1}$ Stromal cell-derived factor (SDF)- $1 \alpha$ is cognate ligand of CXCR4 and high levels expression of SDF1 $\alpha$ /CXCR4 axis is associated with lung, liver and lymph nodes metastasis. ${ }^{2}$ SDF1 $\alpha$ /CXCR4 axis plays key role in human development, including organogenesis, vascularisation, haematopoiesis, and embryogenesis. ${ }^{3}$ More recent evidence shows that the SDF-1 $\alpha$ /CXCR4 axis acts as key regulator of metastasis in leukemia \& several solid tumors and also plays an important role in self renewal, differentiation potential, cell adhesion, tumorigenicity \& tumor vascularization capacity of tumor cell.,4 CD133 is a 5-transmembrane cell surface glycoprotein expressed in subpopulation of CD34p haematopoietic stem and progenitor cells derived from human fetal liver and bone marrow. ${ }^{6}$ CD133 expression has been detected in normal tissues like neuroepithelium stem cells in mice, embryonic \& adult immature epithelia and also considered as well studied cancer stem cell marker. ${ }^{7}$ Although the exact function of CD133 expression in tumor tissues is still not 
clear however could serve as a prognostic indicator for tumor re-growth, malignant progression, and patient survival. Expression of CD133 is involved in bioenergetic stress, resistance to apoptosis and the activation of a stemness-related signaling pathway. ${ }^{8}$ Various studies suggests that CSC co-expressing CXCR4 and CD133 is highly tumorigenic, and found to be expressed in malignant Rhabdoid tumor of the kidney (MRTK) in infant, metastatic Pancreatic cancer, and Renal cell carcinoma. ${ }^{9-11}$ In this study, immunohistochemistry and immunofluorescence method was used to study the expression of CXCR4 and CD133 in gastric cancer. RT-PCR also supports the expression pattern of these two regulatory molecules. Discussion on the relationship of CXCR4 and CD133 in gastric cancer tissues may be helpful to establish the biological behaviour and prognosis of gastric cancer and may also helpful for studying molecular drug targeting.

\section{Methods and Materials}

\section{Study population and tissue specimens}

The biopsy specimens of gastric cancer were obtained from 70 patients of Department of Gastroenterology, Stanley Medical College and Hospital, Chennai, Tamil Nadu, India. The study was approved by the ethics committee of the Stanley Medical College and Hospital. Written informed consents were obtained from all the patients for participation in the study. Additionally 20 resected specimens following gastrectomy for stomach malignancy were also included for the study. Another 30 cases of adjacent normal gastric mucosa (by gastroscopic biopsy) were used as control.

The study group was consisted of 90 patients, male 68 cases and female 22 cases (25-75 years of age, the median age of 50 years). Stage, grade and histological types were defined after histopathological examination. There were 25 cases of upper gastric malignancy, 30 cases of middle malignancy and 35 cases of antral malignancy. In the all, 38 cases had tumor size $(<4 \mathrm{~cm})$ and the other 24 cases had large tumor size $>8 \mathrm{~cm}$, and 28 patients had tumour size in between $4-8 \mathrm{~cm}$. There were mucosal tumour 14 cases, 35 cases of sub mucosal tumour, 26 cases of Muscularis Propia tumour and 15 cases of Sub Serosa tumour. There were 54 cases with lymphatic invasion and 51 cases with node metastasis of tumour. Patients in the study group had no history of undergoing chemotherapy or radiation therapy.

\section{Immunohistochemistry and immunofluorescence study}

Experimental paraffin block samples were used for serial tissue sectioning, $4 \mu \mathrm{m}$ thickness underwent $\mathrm{HE}$, as well as IHC staining respectively. The endogenous peroxidise activity was blocked by $3 \% \mathrm{H}_{2} \mathrm{O}_{2}$ and non-specific binding was blocked with $3 \%$ BSA in $1 \mathrm{x}$ PBS at room temperature. The sections were then incubated overnight at $4^{\circ} \mathrm{C}$ with primary antibodies for anti-CXCR4, and anti-CD133 (1:300), (Santa
Cruz Biotechnology-USA). The slides were washed in 1x PBS and incubated with the corresponding secondary antibody conjugated with HRP. The peroxidase reaction was developed by hydrogen peroxide in $1 \mathrm{x}$ PBS as substrate and 3,3'-diaminobenzidine tetrachloride as chromogen. The sections were counter stained with Mayer's haematoxylin and mounted with DPX after proper dehydration. Positive control sections were prepared to confirm the reactivity of the antibody whereas negative control sections were prepared by substituting PBS instead of primary antibody.

For immunofluorescence studies, after incubation with primary antibodies, fluorescent conjugated secondary antibodies were used (FITC- conjugated anti-mouse for CXCR4 and Alexa 592 (red) anti-goat for CD133) and later on the slides were counterstained using DAPI. The sections were mounted and examined under confocal microscopy (Leica TCS2XL Spectra confocal-Multiphoton microscopy).

\section{Evaluation of immunostaining}

The intensity and cellular localization of immunostained CXCR4 and CD133 was evaluated in a semi-quantitative fashion. Staining intensity was graded in 0-3 scale (0- no staining, 1- shallow brown, 2- Brown, 3- dark brown). Positive cells were also graded in $0-3$ scale $(0$ - no staining, $1<$ $25 \%$ staining cells, $2<25-50 \%$ staining cells and $3>50 \%$ staining cells). The final scores were given as,,-+++ and +++ which were summation of staining percentages and intensity; and considered as negative, mild, moderate and intense respectively. Distinct membranous to cytoplasmic expression of CD133 was considered as positive expression whereas discrete cytoplasmic expression was considered as positive CXCR4.

\section{Reverse transcriptase PCR}

RNA was extracted using Isol-RNA Lysis Reagent (5'PRIME Inc, Gaithersburg, USA) according to the manufacturer's protocol. The RNA concentration was determined by Biophotometer (Eppendorf, Germany) and total RNA (1 mg) was used to generate cDNA using standard method. The reactions were cycled after an initial denaturation at $94^{\circ} \mathrm{C}$ for 5 min followed by 39 cycles of denaturation at $94^{\circ} \mathrm{C}$ for 30 sec, annealing at $60^{\circ} \mathrm{C}$ for $30 \mathrm{sec}$, and polymerization at $72^{\circ} \mathrm{C}$ for 60 sec. Final extension was done at $72^{\circ} \mathrm{C}$ for $5 \mathrm{~min}$. $\beta$-actin was used as housekeeping gene. The PCR products were electrophoresed on $1.2 \%$ agarose gels with ethidium bromide and visualized in UV light (VilberLourmat, France).

\section{Statistical analysis}

The $\chi^{2}$ test was used for the percentage of samples with positive staining among lesions of different histological grades using StatCalc 5.0.4 (AcaStat software).The independent student's $t$-test was used for statistical significant in western 
blot analysis. $p<0.05^{*}$ was considered statistically significant and $p<0.01^{* *}$ was considered as highly significant.

\section{Results}

The expression of CXCR4 and CD133 in gastric cancer and adjacent normal gastric mucosa

IHC assay showed that CXCR4 positive staining mainly localized on cell cytoplasm (Figure 1A), and brownish granule of CD133-positive were visible in cytoplasm and the cell membrane (Figure 1B), which both didn't express in gastric normal tissues. The positive rate of CXCR4 expression was 85/90 (94.44\%) and 7/30 (23.23\%) in gastric cancer and adjacent normal tissues, with statistically significant differences $\left(p<0.001^{* *}\right)$ (Table 1). To CD133, positivity in gastric cancer was $95.55 \%$ (86/90), very mild expression 5/30 (16.66\%) in the adjacent normal tissues was found, showing strong differences $\left(p<0.001^{* *}\right)$ (Table 2).

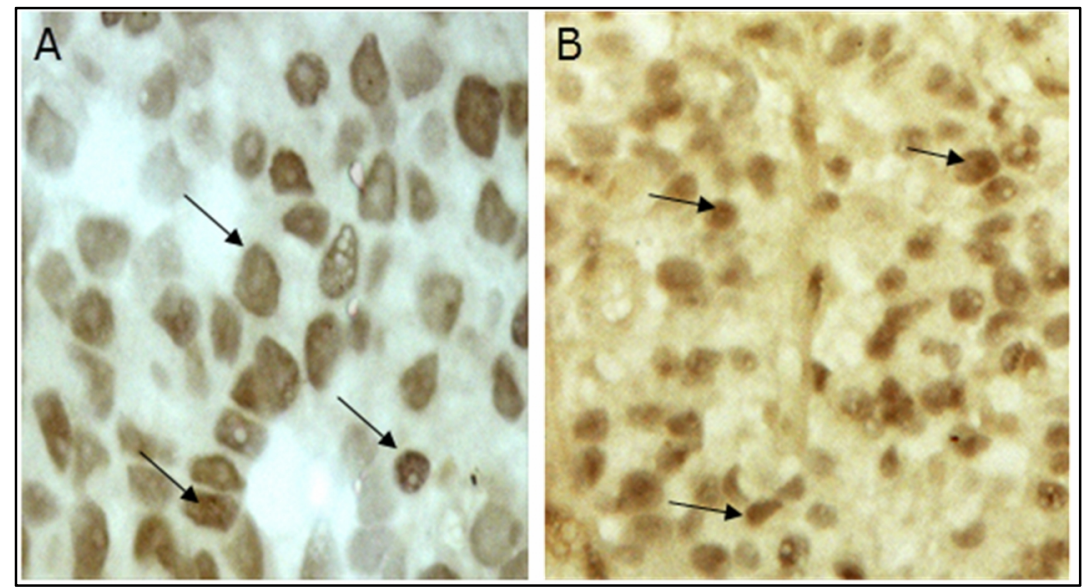

FIG. 1: Immunohistochemical analysis shows overexpression of CXCR4 and CD133 in human gastric cancer. A) Expression of CXCR4 mainly localized in the cell cytoplasm; B) Positive staining of CD133 localized in cytoplasm and cell membrane. (Magnification in 20X).

TABLE 1: Expression of CXCR4 in gastric cancer and normal tissue.

\begin{tabular}{lcccccccc}
\hline \hline $\begin{array}{l}\text { Clinicopathological } \\
\text { stages }\end{array}$ & \multicolumn{2}{l}{$\begin{array}{l}\text { Differential expres- } \\
\text { sion pattern }\end{array}$} & $\begin{array}{l}\text { Number of } \\
\text { cases }(\mathrm{n}=120)\end{array}$ & $\begin{array}{l}\text { Positive } \\
\text { rate\% }\end{array}$ & $\chi^{2}$ & $p$ value \\
\cline { 2 - 5 } & - & + & ++ & +++ & & & & \\
\hline Normal gastric mucosa & 23 & 7 & 0 & 0 & 30 & 23.23 & & - \\
Adenocarcinoma & 5 & 12 & 26 & 47 & 90 & 94.44 & 74.516 & $0.000^{* *}$ \\
\hline \hline
\end{tabular}

a. Calculated using $\chi^{2}$

b. $\quad 0.000=<0.001^{* *}$ denotes significance at $1 \%$ level.

TABLE 2: Expression of CD133 in gastric cancer and normal tissue.

\begin{tabular}{lcccccccc}
\hline \hline $\begin{array}{l}\text { Clinicopathological } \\
\text { stages }\end{array}$ & \multicolumn{2}{l}{$\begin{array}{l}\text { Differential expres- } \\
\text { sion pattern }\end{array}$} & $\begin{array}{l}\text { Number of } \\
\text { cases }(\mathrm{n}=120)\end{array}$ & $\begin{array}{l}\text { Positive } \\
\text { rate\% }\end{array}$ & $\chi^{2}$ & $p$ value \\
\cline { 2 - 6 } & - & + & ++ & +++ & & & \\
\hline $\begin{array}{l}\text { Normal gastric mucosa } \\
\text { Adenocarcinoma }\end{array}$ & 24 & 5 & 1 & 0 & 30 & 16.66 & & - \\
\hline \hline
\end{tabular}

a. Calculated using $\chi^{2}$

b. $\quad 0.000=<0.001^{* *}$ denotes significance at $1 \%$ level.

\section{Coimmunolocalization of CXCR4 and CD133 in gastric tissues}

Coimmunofluorescence of CXCR4 and CD133 was performed in normal and adenocarcinoma tissue sections of gastric tissues (Figure 2). CXCR4 was conjugated with anti-Mouse FITC (green) and CD133 with anti-Goat Alexa fluor (red). Merged image shows yellow color which indi- cates their colocalization. CXCR4 and CD133 were principally colocalized in cytoplasm of adenocarcinoma, while it was not observed in normal tissues. This result showed interesting evidence for intracellular convergence of CXCR4 and CD133 during gastric adenocarcinoma progression and its prognosis (Figure 2). 

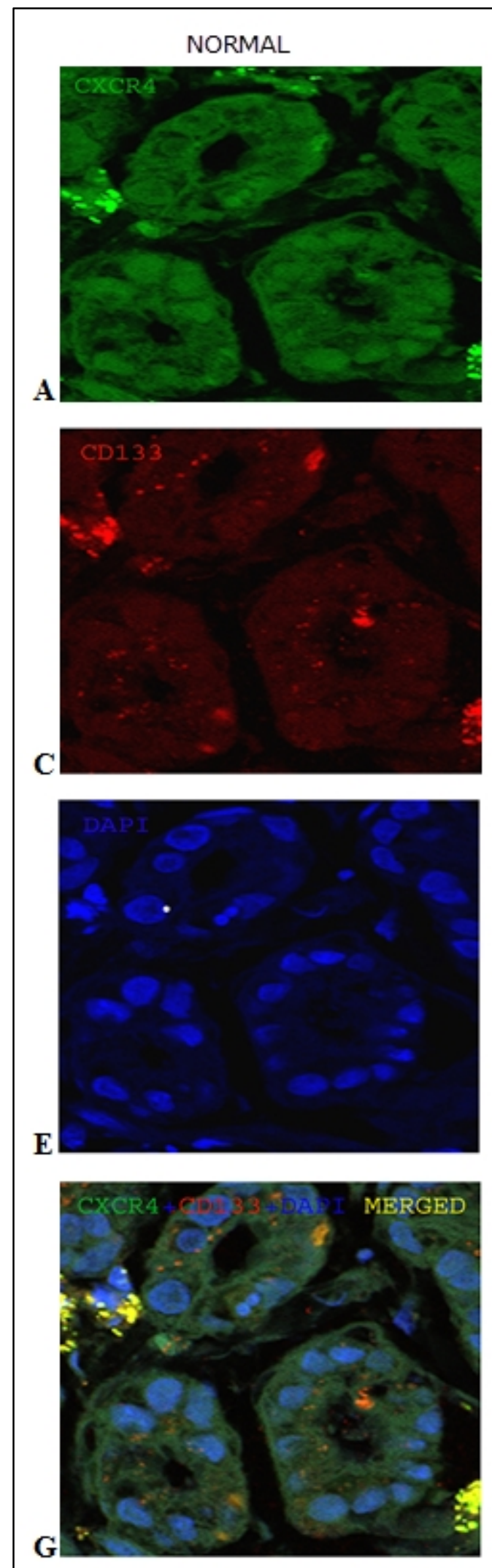

\section{ADENOCARCINOMA}

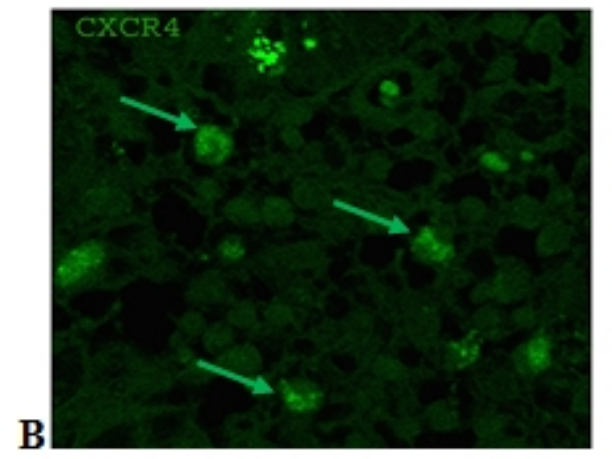

D
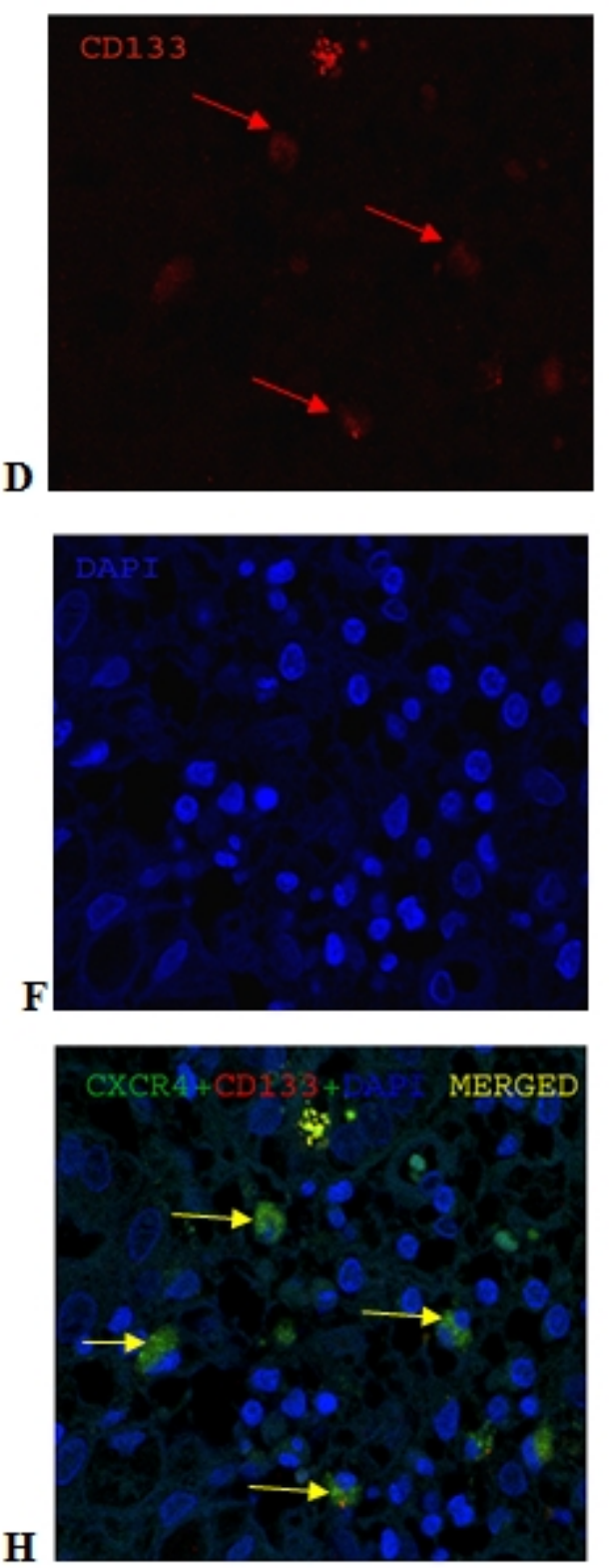

FIG. 2: Co-immunolocalisation of CXCR4 and CD133 in gastric epithelial tissue. The expression of both CXCR4 (A-B) and CD133 (C-D) in the same field of gastric tissue by immunofluorescence using FITC (green) for CXCR4 and Alexa fluor (red) for CD133). The tissues were counterstained with DAPI (E-F) Merged image of CXCR4, CD133 and DAPI (G-H). (Magnification in 60X). 


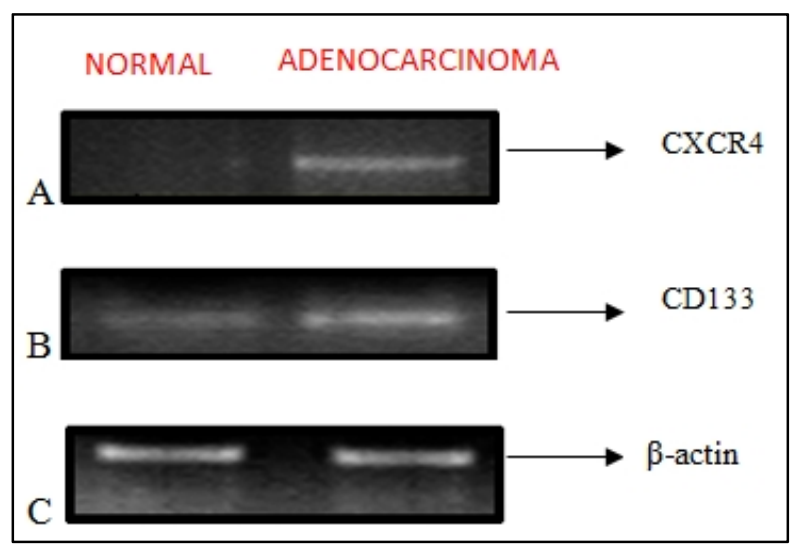

FIG. 3: RT-PCR analysis shows CXCR4 \& CD133 m-RNA expression in human gastric tissues. A) CXCR4 m-RNA transcript was amplified in normal and carcinoma tissue; B) CD133 m-RNA transcript was amplified in normal and carcinoma tissue; C. $\beta$-actin m-RNA transcript was amplified in normal and carcinoma tissue.

TABLE 3: Relationship between expression of CXCR4 and CD133 in gastric cancer.

\begin{tabular}{cccccc}
\hline $\begin{array}{c}\text { Expression of } \\
\text { CXCR4 }\end{array}$ & $\mathrm{n}=\mathbf{9 0}$ & \multicolumn{4}{c}{ Expression of CD133 } \\
\hline & & $0(5)$ & $1^{+}(12)$ & $2^{+}(26)$ & $3^{+}(47)$ \\
\hline 0 & 4 & 2 & 1 & 1 & 0 \\
$1^{+}$ & 14 & 1 & 2 & 9 & 2 \\
$2^{+}$ & 27 & 2 & 7 & 12 & 6 \\
$3^{+}$ & 45 & 0 & 2 & 4 & 39 \\
\hline
\end{tabular}

a. Significant Positive correlation found in between CXCR4 expression and CD133 expression in gastric cancer $\left(\chi^{2}=58.657\right)\left(p<0.001^{* *}\right)$.

TABLE 4: Expression of CXCR4 and correlation with clinicopathological factors in gastric cancer.

\begin{tabular}{|c|c|c|c|c|c|}
\hline Parameters & $\mathrm{n}$ & $\begin{array}{l}\text { CXCR4 } \\
(+\mathrm{ve})\end{array}$ & $\begin{array}{c}\text { CXCR4 } \\
\text { (-ve) }\end{array}$ & $\chi^{2}$ & $p$-value \\
\hline \multicolumn{6}{|l|}{ Age } \\
\hline$<=50$ & 55 & 52 & 3 & 0.003 & 0.958 \\
\hline$\geq>=50$ & 35 & $\underline{3} 3$ & 2 & & \\
\hline \multicolumn{6}{|l|}{ Gender } \\
\hline Male & 68 & 66 & 2 & 3.624 & 0.057 \\
\hline Female & 22 & 19 & 3 & & \\
\hline \multicolumn{6}{|l|}{ Tumor Position } \\
\hline Upper & 25 & 24 & 1 & 0.188 & 0.910 \\
\hline Middle & 30 & 28 & 2 & & \\
\hline Lower & 35 & 33 & 2 & & \\
\hline \multicolumn{6}{|l|}{ Tumor Size } \\
\hline$<4$ & 38 & 26 & 12 & 7.025 & $0.030^{*}$ \\
\hline $4-8$ & 28 & 23 & 5 & & \\
\hline$\ldots$ & 24 & 23 & 1 & & \\
\hline \multicolumn{6}{|l|}{ Tumor Depth } \\
\hline Mucosa & 14 & 8 & 6 & & \\
\hline Sub Mucosa & 35 & 30 & 5 & 10.113 & $0.018^{*}$ \\
\hline Muscularis Propia & 26 & 24 & 2 & & \\
\hline Subserosa & 15 & 14 & 1 & & \\
\hline \multicolumn{6}{|l|}{ Lymphatic Invasion } \\
\hline (+ve) & 54 & 39 & 15 & 4.59 & $0.032^{*}$ \\
\hline \multirow{2}{*}{\multicolumn{6}{|c|}{$\begin{array}{c}(-\mathrm{ve}) \\
\text { Node Metastasis }\end{array}$}} \\
\hline & & & & & \\
\hline (+ve) & 51 & 37 & 14 & 6.48 & $0.011^{*}$ \\
\hline (-ve) & 39 & 18 & 21 & & \\
\hline
\end{tabular}


TABLE 5: Expression of CD133 and and correlation with clinicopathological factors in gastric.

\begin{tabular}{|c|c|c|c|c|c|}
\hline Parameters & $\mathrm{n}$ & $\begin{array}{c}\text { CD133 } \\
\text { (+ve) }\end{array}$ & $\begin{array}{r}\text { CD133 } \\
\text { (-ve) } \\
\end{array}$ & $\chi^{2}$ & $p$-value \\
\hline \multicolumn{6}{|l|}{ Age } \\
\hline$<=50$ & 55 & 54 & 1 & 2.297 & 0.130 \\
\hline$>=50$ & 35 & 32 & 3 & & \\
\hline \multicolumn{6}{|l|}{ Gender } \\
\hline Male & 68 & 66 & 2 & 1.480 & 0.224 \\
\hline Female & 22 & 20 & 2 & & \\
\hline \multicolumn{6}{|l|}{ Tumor Position } \\
\hline Upper & 25 & 24 & 1 & 0.232 & 0.891 \\
\hline Middle & 30 & 29 & 1 & & \\
\hline Lower & 35 & 33 & 2 & & \\
\hline \multicolumn{6}{|l|}{ Tumor Size } \\
\hline$<4$ & 38 & 24 & 14 & 6.673 & $0.036^{*}$ \\
\hline $4-8$ & 28 & 22 & 6 & & \\
\hline$>8$ & 24 & 22 & 2 & & \\
\hline \multicolumn{6}{|l|}{ Tumor Depth } \\
\hline Mucosa & 14 & 9 & 5 & & \\
\hline Sub Mucosa & 35 & 30 & 5 & 9.120 & $0.028^{*}$ \\
\hline Muscularis Propia & 26 & 24 & 2 & & \\
\hline Sub serosa & 15 & 15 & 0 & & \\
\hline \multicolumn{6}{|l|}{ Lymphatic Invasion } \\
\hline$(+\mathrm{ve})$ & 54 & 38 & 16 & 4.87 & $0.027^{*}$ \\
\hline$(-\mathrm{ve})$ & 36 & 17 & 19 & & \\
\hline \multicolumn{6}{|l|}{ Node Metastasis } \\
\hline$(+\mathrm{ve})$ & 51 & 39 & 12 & 6.21 & $0.013^{*}$ \\
\hline (-ve) & 39 & 20 & 19 & & \\
\hline
\end{tabular}

Correlation between CXCR4 and CD133 expression in gastric adenocarcinoma

The correlation between CXCR4 and CD133 expression in gastric adenocarcinoma tissues were shown using spearman rank correlation study (Table 3). Statistically significant positive correlation was found between CXCR4 and CD133 expression in gastric adenocarcinoma $\left(\chi^{2}=58.657\right)$.

CXCR4 and CD133 m-RNA expression in gastric cancer and adjacent normal gastric mucosa

RT-PCR analysis was done to show the presence of CXCR4 and CD133 m-RNA in gastric tissue samples. In gastric adenocarcinoma tissues m-RNA transcript was present for both CXCR4 and CD133 whereas adjacent normal gastric tissue was showing very mild expression (Figure 3 ). $\beta$ - actin was used as positive control.

\section{Relationship between CXCR4 \& CD133 expression and clinicopathological factors}

In the multivariate analysis, the expressions of CXCR4 and CD133 were both unrelated to gender, age of the patient, and position of the tumor but had relationship with size of the tumour and depth of the tumour. The expression of CXCR4 and CD133 also correlated with lymphatic invasion and node metastasis. Both CXCR4 $\left(p<0.05^{*}\right)$ \& CD133 $\left(p<0.05^{*}\right)$ expression and tumor size correlated significantly and strongly. The depth of the tumor and expression of CXCR4 $\left(p<0.05^{*}\right)$ and CD133 $\left(p<0.05^{*}\right)$ was also correlated significantly and strongly. Lymphatic invasion of the tumor and expression of CXCR4 $\left(p<0.05^{*}\right)$ and CD133 $\left(p<0.05^{*}\right)$ were correlates significantly. Expression of Node metastasis and CXCR4 $\left(p<0.05^{*}\right)$ and CD133 $\left(p<0.05^{*}\right)$ expression were also correlated significantly (Table 4 and Table 5 ).

\section{Discussion}

Tumor prognosis is a dynamic process involving multiple molecular and cellular mechanisms. CXCR4 expression has been studied in breast cancer, prostate cancer, liver cancer and renal cancer. In this study, analysis of expression pattern of CXCR4 demonstrates the role of migratory CSC in invasiveness of gastric cancer. CXCR4 positive staining was found in $94.44 \%$ (85/90) gastric cancer samples which was higher than non-malignant tissues $\left(p<0.001^{* *}\right)$. In breast cancer, presence of CXCR4+ cell indicates existence of cancer stem cells and corroborates its potential role in the acquisition of more aggressive tumor features. ${ }^{12}$ In concomitant to this report our study also suggests that increased expression of CXCR4 in cytoplasm of cancer cells could be associated with invasiveness of the disease.

Our RT-PCR analysis demonstrates that CXCR4 expression is increased in adenocarcinoma than that of normal gastric 
mucosa. There was no correlation found between CXCR4 positivity and gender, age of the patient and position of the tumor. Meanwhile, as we are found CXCR4 positivity was significantly correlated with tumor size $\left(p<0.05^{*}\right)$, depth of the tumor $\left(p<0.05^{*}\right)$, lymphatic invasion $\left(p<0.05^{*}\right)$ and node metastasis $\left(p<0.05^{*}\right)$, was consistent with the study of Jun Miki et al. in prostate cancer and the study by Satoshi et al. in intestinal type gastric carcinoma. ${ }^{13,14}$ Distinct immunostaining pattern of CXCR4 in cytomembrane and/or nucleus is associated with high tumor stage of liver carcinoma and metastasis of ranal cancer. ${ }^{15,}{ }^{16}$ In the light of this report our results indicate that high expression of CXCR4 may be correlated with symptomatic and advanced stages of disease and suggesting their definitive role in prognosis of the disease.

CD133 was considered as one of the most prominent CSC marker which is associated with cell movement and asymmetric cell division. CD133 was found to be over expressed in hepatocarcinoma, gastric cancers, colorectal cancer, pancreatic cancer and other types of cancer. In hepatocellular carcinoma, presence of CD133+ staining in minor populations of cells may be indicative of cancer stem-like cells which lead to tumor recurrence and metastasis. ${ }^{17}$ In the light of these report our study also showed that increased expression of CD133 in $95.55 \%$ (86/90) gastric cancer samples which was higher than non-malignant tissues $\left(p<0.05^{*}\right)$ and our RT-PCR data also suggests that the expression of CD133 is increased in adenocarcinoma than in normal gastric tissue. These findings suggest that CD133 can be considered as CSC marker for gastric cancer and its expression are correlated with malignant progression and suggesting their definitive role in cancer tissues. The results of our study are similar to that reported by Ji-wei $\mathrm{Y}$ in gastric carcinoma ${ }^{18}$, a study by Horst D, who established CD133 expression as a prognostic marker in colorectal cancer ${ }^{19}$ and the study by Harmaann in CD133+ pancreatic CSCs ${ }^{10}$. There was no correlation found between CD133 positivity and gender, age of the patient and position of the tumor. Our study also showed that CD133 positivity was significantly correlated with tumor size $\left(p<0.05^{*}\right)$, depth of the tumour $\left(p<0.05^{*}\right)$, lymphatic invasion $\left(p<0.05^{*}\right)$ and node metastasis $\left(p<0.05^{*}\right)$. From these observations, it can be concluded that high cytoplasmic expression of CD133 is correlated with poor prognosis, invasion and higher recurrence rates of the malignant cells.

In this study we have also analyzed the expression pattern of CXCR4 in the distinct population of CD133+ cell in gastric cancer tissue. In the malignant tissue, $92.22 \%$ of CXCR4+ cells were expressing CD133. In colon cancer cell, CXCR4-expressing CD133+ cells from the primary tumour region might play significant role in recruitment of metastasing cells. ${ }^{20}$ In concomitant to this data our findings also showed the presence of CXCR4+ CD133+ cells which might transmit the signal for creating receptive microenvironments and followed by recruitment of metastasizing cells.
Our findings were similar with a study by Shan-shan et al., which indicate the potential involvement of CXCR4 and CD133 in CRC metastasis to the liver in vitro. ${ }^{21}$ According to our study, CXCR4 and CD133 protein expression in gastric cancer displayed a significant correlation, which pointed out co-expression of CXCR4 \& CD133 is associated with higher migratory and invasive capacities of tumor cells and might play an important role in the migration of cancer stem cell.

\section{Conclusion}

In conclusion, our data support the previous studies which analyze expression of both CD133 and CXCR4 in solid tumours. The increased expression of CXCR4 and CD133 in adenocarcinoma implies their possible tumour inducing capacities in human gastric carcinoma. This study also suggests that increased co-expression of CXCR4 \& CD133 could be considered as migratory cancer stem cell and is associated with poor prognosis and invasion of gastric cancer. Moreover, extensive studies on regulation of expression of these markers may reveal their possibilities as therapeutic implication.

\section{Conflict of interest}

The authors declare that they have no conflicts of interest. The authors alone are responsible for the content and writing of the paper.

\section{References}

1. Stein JV, Nombela-Arrieta C. Chemokine control of lymphocyte trafficking: a general overview. Immunology. 2005; 116:1-12.

2. Wang B, Wang W, Niu W, et al. SDF-1/CXCR4 axis promotes directional migration of colorectal cancer cells through up regulation of integrin $\alpha v \beta 6$. Carcinogenesis. 2014; 35:282-91.

3. Takabatake Y, Sugiyama $\mathrm{T}$, Kohara $\mathrm{H}$, et al. The CXCL12 (SDF-1)/CXCR4 axis is essential for the development of renal vasculature. J Am Soc Nephrol. 2009;20:1714-23.

4. Dommange F, Cartron G, Espanel C, et al. CXCL12 polymorphism and malignant cell dissemination/tissue infiltration in acute myeloid leukemia. FASEB J. 2006; 20:1913-5.

5. Koshiba T, Hosotani R, Miyamoto Y, et al. Expression of stromal cell-derived factor 1 and CXCR4 ligand receptor system in pancreatic cancer: apossible role for tumor progression. Clin Cancer Res. 2000;6:3530-5.

6. Yin AH, Miraglia S, Zanjani ED, et al. AC133, a novel marker for human hematopoietic stem and progenitor cells. Blood.1997;90:5002-12. 
7. Choi SA, Wang KC, Phi JH, et al. A distinct subpopulation within CD133 positive brain tumor cells shares characteristics withendothelial progenitor cells. Cancer Lett. 2012;324:221-30.

8. Li Z. CD133: a stem cell biomarker and beyond. Exp Hematol Oncol.2013;2:17.

9. Yanagisawa S, Kadouchi I, Yokomori K, et al. Identification and metastatic potential of tumor -initiating cells in malignant rhabdoid tumor of the kidney. Clin Cancer Res. 2009; 15:3014-22.

10. Hermann PC, Huber SL, Herrler T, et al. Distinct populations of cancer stem cells determine tumor growth and metastatic activity in human pancreatic cancer. Cell Stem Cell. 2007; 1:313-23.

11. D'Alterio C, Consales C, Polimeno MN, et al. Concomitant CXCR4 and CXCR7 expression predicts poor prognosis in renal cancer. Curr Cancer Drug Targets. 2010; 10:772-81.

12. Dubrovska A, Hartung A, Bouchez LC, et al. CXCR4 activation maintains a stem cell population in tamoxifen-resistant breast cancer cells through AhRsignalling. Br J Cancer. 2012; 107:43-52.

13. Miki J, Furusato B, Li H, et al. Identification of putative stem cell markers: CD133 and CXCR4, in hTERT-immortalized primary nonmalignant and malignant tumor-derived human prostate epithelial cell lines and in prostate cancer specimens. Cancer Res. 2007; 67:3153-61.

14. Iwasa S, Yanagawa T, Fan J, Katoh R. Expression of CXCR4 and its ligand SDF-1 in intestinal-type gas- tric cancer is associated with lymph node and liver metastasis. Anticancer Res. 2009;29:4751-8.

15. Shibuta K, Mori M, Shimoda K, et al. Regional expression of CXCL12/CXCR4 in liver and hepatocellular carcinoma and cell-cycle variation during in vitro differentiation. Jpn J Cancer Res. 2002; 93:789-97.

16. D'Alterio C, Cindolo L, Portella L, et al. Differential role of CD133 and CXCR4 in renal cell carcinoma. Cell Cycle. 2010;9:4492-500.

17. Suetsugu A, Nagaki M, Aoki H, et al. Characterization of CD133+ hepatocellular carcinoma cells as cancer stem/progenitor cells. BiochemBiophys Res Commun. 2006; 351:820-4.

18. Yu JW, Zhang P, Wu JG, et al. Expressions and clinical significances of CD133 protein and CD133 mRNA in primarylesion of gastric adenocacinoma. J ExpClin Cancer Res. 2010;29:141.

19. Horst D, Kriegl L, Engel J, et al. CD133 expression is an independent prognostic marker for low survival in colorectal cancer. Br J Cancer. 2008; 99:1285-9.

20. Chao C, Carmical JR, Ives KL, et al. CD133+ colon cancer cells are more interactive with the tumor microenvironment than CD133- cells. Lab Invest. 2012; 92:420-36.

21. Shan-shan Z, Zhi-peng H, Ying-ying J, et al. CD133+CXCR4+ colon cancer cells exhibit metastatic potential and predict poor prognosis of $\mathrm{pa}^{-}$ tients. BMC Med. 2012; 10:85. 